\title{
Treatment of scleroderma with para-aminobenzoic acid: effect on disease morbidity.
}

\author{
Khalid Sawalha* \\ Department of Neurology, Ohio State University Wexner Medical Center, 395 W. 12th Avenue, 7th Floor, Columbus, OH 43210, USA
}

\begin{abstract}
This is an expedited review of literature that dives into the less well-known aspects of Scleroderma, also known as systemic sclerosis. Scleroderma is an autoimmune chronic systemic inflammatory disorder of the connective tissue that is characterized by collagen deposition in the skin and other internal organs. The incidence of scleroderma in the United States is approximately 20 cases per million per year while the estimated prevalence is $\mathbf{2 4 0}$ cases per million. The incidence is higher in African Americans and more prevalent in women than in men (4.6:1). Although the etiology of scleroderma is not well identified, exposure to environmental factors, including viruses, certain toxins or drugs, may provoke the disease in genetically susceptible hosts. Collagen deposition and fibrosis of the skin and body organs, such as lung, esophagus, and heart is the reason for the variable clinical presentations of scleroderma. Hardening of the skin and dysphagia, are the most common presentation of scleroderma. Scleroderma is a devastating disease that decreases the quality of life significantly. Pulmonary and cardiac involvement is the leading cause of death. As the pathogenesis of scleroderma is poorly understood, and due to the variable manifestation of the disease, there is no curative treatment available to date. The management usually targets the symptomatology and it is customized based on the involved internal organ. Immunotherapy has been widely used in the treatment of scleroderma; however, its efficacy has not been well established. Other alternative symptomatic therapy including Para-aminobenzoic acid decreases the progression of skin fibrosis and improves survival.
\end{abstract}

Keywords: Scleroderma, Systemic sclerosis, Para-aminobenzoic acid, Mortality, Morbidity.

Accepted on April 27, 2018

\section{Introduction}

Scleroderma is a chronic systemic disfiguring spectrum of disorders that affects connective tissues in skin, blood vessels and internal organs. The pathogenesis of scleroderma is characterized by three hallmarks: activation of the immune system, disruption blood vessel wall, and excessive synthesis and deposition of collagen in the skin and visceral organs. The consequences of such pathogenesis are based on the amount of systemic response produced by the inflammation. Early immunological events and vascular damage lead to the production of activated fibroblasts which cause fibrosis [1]. Fibrosis is the leading mechanism behind the clinical presentation of scleroderma and its severity. The etiology of scleroderma can be multifactorial and it is poorly understood. Exposure to environmental factors, including viruses, certain toxins or drugs, may provoke the disease in genetically susceptible hosts [2]. While scleroderma is not identified as an inherited disease, genetic components might play a role in the development of the disease. Incidence of the disease is $(1.6 \%)$ among families while it is only $(0.026 \%)$ in general population. Clinical manifestations, natural history, response to treatment, and outcomes are remarkably variable between scleroderma patients [3]. Based on the extent of skin fibrosis and the pattern of internal organ involvement, scleroderma spectrum of disorders are classified into two main forms. Localized scleroderma that affects only the skin and systemic scleroderma, or systemic sclerosis, that extends to affect multiple body organs [4]. Localized scleroderma is further classified to, Morphea and Linear scleroderma. Morphea is waxy patches on the skin of different sizes, shapes and color while the linear type is a line of hardened, waxy skin on an arm or a leg or on the forehead [5]. Systemic scleroderma is classified into three categories; (i) Diffuse Scleroderma which involves skin thickening and internal organs sclerosis, (ii) Sine Scleroderma which involves organ fibrosis with no skin involvement and (iii) Limited Scleroderma (CREST syndrome: Calcinosis, Raynaud's phenomenon, Esophageal dysmotility, Sclerodactyly, and Telangiectasia) [6].

\section{Epidemiology}

Systemic scleroderma is a rare disease with an Incidence estimated to be 3-24 cases per million per year and prevalence ranging from 150 to 300 cases per million [7]. Because of its rarity and clinically variable presentations, there are no reliable epidemiological studies that accurately identify its prevalence. The prevalence usually varies by ethnicity, gender and geographic area. The prevalence is (150 per million) in Northern Europe and Japan and higher (276-443 per million) in Southern Europe, North America, and Australia [8]. As in many other autoimmune diseases, women are at higher risk than men (4.6:1 ratio over men). African Americans have higher incidence and prevalence and express more severe symptoms and have even higher mortality [9]. Scleroderma can occur at any age; however, it is rare in children and elderly. The peak onset occurs in individuals aged 30-50 years. Limited scleroderma is more common in children and while systemic types are more common in adults [10]. 


\section{Pathogenesis}

Connective tissues are the structural frame of the human body that in essence clamps cells together. It is developed from the mesoderm and it gives the body its shape [11]. In connective tissue disorders, distortion of connective tissue will lead to disfiguring due to its replacement by fibrous tissue that causes limitations in mobility and activities of daily living. Scleroderma pathophysiology is poorly understood due to the variability of the clinical picture accompanied by the disease rarity. Understanding the pathophysiology is crucial to the development of the proper treatment.

There are several pathological processes from the development of the scleroderma till the complete damage and fibrosis. The pathogenesis of the scleroderma is similar to the natural healing process of the body in response to injury. Dysregulation of innate and adaptive immunity, a small-vessel vasculopathy, and an extensive fibrosis and collagen deposition into the skin and visceral organs are the main hallmarks of the disease process $[12,13]$. The pathogenesis of scleroderma is likely initiated by the exposure of a genetically susceptible host to an external event that leads to microvascular injury and endothelial cell abnormalities. Adhesion molecules such as intercellular adhesion molecule-1 (ICAM-1), vascular cell adhesion molecule-1 (VCAM-1), and endothelial leukocyte adhesion molecule-1 (E-selectin) are upregulated in response to cytokines and other factors following inflammation and damage to the vascular endothelium. These endothelial adhesion molecules bind to specific integrin on $\mathrm{T}$ and B cells, neutrophils, monocytes, and natural killer (NK) cells. This will result in adhesion and subsequent migration of these cells through leaky endothelium and into the extracellular matrix [14]. The Endothelial cells also produce endothelin-1 and connective tissue growth factor, which activate vascular smooth-muscle cell proliferation and ECM production leading to thickening of blood vessels walls. As a result, disturbance of microvasculature and narrowing of the capillary exchange surface area lead to tissue hypoxia which further enhances the ongoing inflammation. This will activate the myofibroblasts and increase smooth cells proliferation which will end up with organ fibrosis and vasculopathy $[15,16]$.

\section{Treatment}

The complex pathophysiology of scleroderma, variety of presentation, progression and body organs involvements make the treatment hard to achieve. The principle of management is based on (1) suppressing the inflammatory and fibrosis process and (2) organ targeted therapy for symptoms improvement. Immunosuppressive medications are widely used to suppress the disease progression, however, clinical trials that evaluate the effectiveness of therapies for systemic sclerosis showed limited efficiency in controlling fibrosis. Tables 1 and 2 present the common immunosuppressive and anti-fibrotic medications respectively and their outcome on the disease activities.

\section{Para-aminobenzoic acid therapy}

Potassium Para-Aminobenzoic Acid, also known as PABA, is a non-protein amino acid PABA is found in diet including eggs, meat and grains. It is an intermediate product in the folic acid pathway which is an important pathway for nucleic acid synthesis and DNA assembly [30]. PABA is frequently found as a structure in many drugs that have a wide range of therapeutic uses, such as: sun-screening, antibacterial, cancer therapy, local anesthetic and anticonvulsants [31]. Para-Aminobenzoic Acid has anti-fibrosis effects due to an ability to increase oxygen consumption by tissues. It is used to treat skin conditions like vitiligo, morphea, scleroderma and Peyronie's disease [32]. It is also used to treat infertility and connective tissue diseases. However, limited evidence is available to support its efficacy. There are several studies on potassium aminobenzoic acid efficacy on systemic sclerosis which show an improvement

Table 1. Immunosuppressive therapy.

\begin{tabular}{|c|c|c|}
\hline Treatment & Mechanism of action & Outcome \\
\hline Cyclosporine & $\begin{array}{l}\text { It decreases IL-2 release which inhibits T-helper cells and reduce } \\
\text { collagen synthesis }\end{array}$ & $\begin{array}{l}\text { Moderate improvement in skin fibrosis. Its use is limited due to } \\
\text { the side effects [17] }\end{array}$ \\
\hline Glucocorticoids & Immediate suppression of cell mediated immunity & $\begin{array}{l}\text { Limited benefits on disease activity. It might be used with other } \\
\text { immune-modulators therapy [18] }\end{array}$ \\
\hline Plasmapheresis & Removes circulating antibodies & Anecdotal evidence on visceral improvement [19] \\
\hline Rituximab & Anti-CD20 and depletion of B lymphocytes & $\begin{array}{l}\text { It improves skin fibrosis condition and prevent worsening of lung } \\
\text { fibrosis [20] }\end{array}$ \\
\hline Methotrexate & $\begin{array}{l}\text { Folic acid antagonist that inhibits dihydrofolate reductase and DNA } \\
\text { synthesis }\end{array}$ & Improve skin fibrosis [21] \\
\hline Cyclophosphamide & $\begin{array}{l}\text { Alkylating agent forms irreversible DNA crosslinks that lead to } \\
\text { apoptosis }\end{array}$ & $\begin{array}{l}\text { Improvement of lung function, dyspnea, and thickening of the } \\
\text { skin [22] }\end{array}$ \\
\hline Azathioprine & Antimetabolite which blocks DNA and RNA synthesis & $\begin{array}{l}\text { Stabilize lung function and prevent progression of lung fibrosis } \\
\text { [23] }\end{array}$ \\
\hline
\end{tabular}

Table 2. Anti-fibrotic therapy

\begin{tabular}{|l|l|l|}
\hline \multicolumn{1}{|c|}{ Treatment } & \multicolumn{1}{c|}{ Mechanism of action } & \multicolumn{1}{c|}{ Outcome } \\
\hline D-Penicillamine & $\begin{array}{l}\text { Inhibits the formation of stable collagen cross-links by forming hydroxy- } \\
\text { lysine aldehyde and lysine groups on collagen precursors. }\end{array}$ & $\begin{array}{l}\text { Minimal improvement on skin fibrosis and has no effect on } \\
\text { internal organs. It is no longer used due to limited benefits and } \\
\text { severe complications. [24,25] }\end{array}$ \\
\hline Interferon -alpha & reduction in type I collagen synthesis by fibroblasts & Has no effect on the outcome [26] \\
\hline Imatinib & $\begin{array}{l}\text { Tyrosine kinase inhibitor which blocks signaling of both platelet-derived } \\
\text { growth factor (PDGF) and transforming growth factor (TGF)-beta. }\end{array}$ & $\begin{array}{l}\text { Improve vital capacity and stabilize lung functions. [27] There } \\
\text { is no strong evidence of its efficacy on skin fibrosis. Few } \\
\text { cases reported improvement [28]. }\end{array}$ \\
\hline potassium aminobenzoic acid & $\begin{array}{l}\text { Anti-fibrosis effects due to an ability to increase oxygen consumption } \\
\text { by tissues. }\end{array}$ & Improve skin sclerosis and lung function. Improve survival [29] \\
\hline
\end{tabular}


in the severity of skin manifestations in scleroderma and an overall improvement in survival, however, the evidence of its efficacy has not been clearly announced due to limited number of enrollments. Furthermore, studies on PABA therapy are very old, where some are from the early 1940s. A Search of the Medline database showed only few publications (22 articles) addressing the use of aminobenzoic acid in systemic sclerosis.

In 1948, Zarafonetis reported that para-aminobenzoic acid appears to have an anti-fibrotic action, suggested by its beneficial effect in patients with Peyronie's disease and Dupuytren's contracture. Also it was proved that PABA is an effective treatment for limited scleroderma [33]. In patients who received this treatment, the skin gradually became softer and progression of fibrosis decreased, with consequently increased range of motion. Moreover, In 1989, A retrospective study done by Zarafonetis and his colleagues to assess 390 scleroderma patients' response to PABA therapy showed a significant decrease in the progression of pulmonary function and vital capacity. Also, it showed a significant improvement in 5-year and 10-years survival rate in patients who received adequate treatment [34-36].

On the other side, a double-blind trial done in 1994 found that administration of $12 \mathrm{~g}$ PABA daily for 48 weeks had no effect on the skin lesions of scleroderma. However, the patients in that study had longstanding disease (mean duration, 8.67 years), which may have been too advanced to respond to PABA. Also many participants withdrew from the study due to undesirable gastrointestinal side effects which makes the trial less reliable [37]. Finally, the evidence of using PABA as a treatment for scleroderma still has not been fully explored and other prospective well designed double blinded trials are needed.

\section{References}

1. Pattanaik D, Brown M, Postlethwaite BC, et al. Pathogenesis of Systemic Sclerosis. Frontiers in Immunology. 2015;6:272.

2. Fett N. Scleroderma: nomenclature, etiology, pathogenesis, prognosis, and treatments: facts and controversies. Clinics in dermatology. 2013;31:432-7.

3. Agarwal SK, Tan FK, Arnett FC. Genetics and genomic studies in scleroderma (systemic sclerosis). Rheumatic Diseases Clinics of North America. 2008;34:17-40.

4. Hachulla E, Launay D. Diagnosis and classification of systemic sclerosis. Clinical Reviews in Allergy \& Immunology. 2011;40:78-83.

5. Careta MF, Romiti R. Localized scleroderma: clinical spectrum and therapeutic update(). Anais Brasileiros de Dermatologia. 2015;90:62-73.

6. Denton CP, Khanna D. Systemic sclerosis. Lancet (London, England). 2017.

7. Mayes MD, Lacey JV Jr., Beebe-Dimmer J, et al. Prevalence, incidence, survival, and disease characteristics of systemic sclerosis in a large US population. Arthritis and rheumatism. 2003;48:2246-55.

8. Ranque B, Mouthon L. Geoepidemiology of systemic sclerosis. Autoimmunity Reviews. 2010;9:A311-8.

9. Reveille JD. Ethnicity and race and systemic sclerosis: how it affects susceptibility, severity, antibody genetics, and clinical manifestations. Current rheumatology Reports. 2003;5:160-7.

10. Chifflot H, Fautrel B, Sordet C, et al. Incidence and prevalence of systemic sclerosis: a systematic literature review. Seminars in arthritis and rheumatism. 2008;37:223-35.

11. Holbrook KA, Byers PH, Pinnell SR. The structure and function of dermal connective tissue in normal individuals and patients with inherited connective tissue disorders. Scanning electron microscopy. 1982;4:1731-44.

12. Katsumoto TR, Whitfield ML, Connolly MK. The pathogenesis of systemic sclerosis. Annual review of pathology. 2011;6:509-37.

13. Trojanowska M. Cellular and molecular aspects of vascular dysfunction in systemic sclerosis. Nature reviews Rheumatology. 2010;6:10.1038/nrrheum.2010.102.

14. Gruschwitz M, von den Driesch P, Kellner I, et al. Expression of adhesion proteins involved in cell-cell and cell-matrix interactions in the skin of patients with progressive systemic sclerosis. Journal of the American Academy of Dermatology. 1992;27:169-77.

15. Fuschiotti P. Current perspectives on the immunopathogenesis of systemic sclerosis. ImmunoTargets and Therapy. 2016;5:21-35.

16. Shi-Wen X, Denton CP, Dashwood MR, et al. Fibroblast matrix gene expression and connective tissue remodeling: role of endothelin-1. The Journal of investigative dermatology. 2001;116:417-25.

17. Gisslinger H, Burghuber OC, Stacher G, et al. Efficacy of cyclosporin A in systemic sclerosis. Clinical and experimental rheumatology. 1991;9:383-90.

18. Iudici M, van der Goes MC, Valentini G, et al. Glucocorticoids in systemic sclerosis: weighing the benefits and risks - a systematic review. Clinical and experimental rheumatology. 2013;31:157-65.

19. Stummvoll GH. Current treatment options in systemic Sclerosis (Scleroderma). Acta medica Austriaca. 2002;29:14-9.

20. Jordan S, Distler JH, Maurer B, et al. Effects and safety of rituximab in systemic sclerosis: an analysis from the European Scleroderma Trial and Research (EUSTAR) group. Annals of the Rheumatic Diseases. 2015;74:1188-94.

21. van den Hoogen FH, Boerbooms AM, Swaak AJ, et al. Comparison of methotrexate with placebo in the treatment of systemic sclerosis: a 24 week randomized double-blind trial, followed by a 24 week observational trial. British Journal of Rheumatology. 1996;35:364-72.

22. Tashkin DP, Elashoff R, Clements PJ, et al. Cyclophosphamide versus placebo in scleroderma lung disease. The New England Journal of Medicine. 2006;354:2655-66. 
23. Poormoghim H, Rezaei N, Sheidaie Z, et al. Systemic sclerosis: comparison of efficacy of oral cyclophosphamide and azathioprine on skin score and pulmonary involvement-a retrospective study. Rheumatology International. 2014;34:1691-9.

24. Jayson MI, Lovell C, Black CM, et al. Penicillamine therapy in systemic sclerosis. Proceedings of the Royal Society of Medicine. 1977;70:82-8.

25. Shah AA, Wigley FM. My Approach to the Treatment of Scleroderma. Mayo Clinic proceedings Mayo Clinic. 2013;88:377-93.

26. Black CM, Silman AJ, Herrick AI, et al. Interferon-alpha does not improve outcome at one year in patients with diffuse cutaneous scleroderma: results of a randomized, double-blind, placebo-controlled trial. Arthritis and Rheumatism. 1999;42:299-305.

27. Fraticelli P, Gabrielli B, Pomponio G, et al. Low-dose oral imatinib in the treatment of systemic sclerosis interstitial lung disease unresponsive to cyclophosphamide: a phase II pilot study. Arthritis Research \& Therapy. 2014;16:R144-R.

28. Moinzadeh P, Hunzelmann N, Krieg T. Pharmacology and rationale for imatinib in the treatment of scleroderma. J Experimental Pharmacology. 2013;5:15-22.

29. Zarafonetis CJ, Dabich L, Skovronski JJ, et al. Retrospective studies in scleroderma: skin response to potassium paraaminobenzoate therapy. Clinical and Experimental Rheumatology. 1988;6:261-8.
30. Mirzaei M, Khayat M, Saeidi A. Determination of paraaminobenzoic acid (PABA) in B-complex tablets using the Multivariate Curve Resolution-Alternating Least Squares (MCR-ALS) method. Scientia Iranica. 2012;19:561-4.

31. Kluczyk A, Popek T, Kiyota T, et al. Drug evolution: p-aminobenzoic acid as a building block. Current Medicinal Chemistry. 2002;9:1871-92.

32. Griffiths MR, Priestley GC. A comparison of morphoea and lichen sclerosus et atrophicus in vitro: the effects of para-aminobenzoate on skin fibroblasts. Acta Dermatovenereologica. 1992;72:15-8.

33. Zarafonetis CJ. Para-aminobenzoic acid therapy in scleroderma and lymphoblastoma cutis. The Journal of Laboratory and Clinical Medicine. 1948;33:1462.

34. Zarafonetis CJ. Clinical use of paraaminobenzoic acid. Texas state Journal of Medicine. 1953;49:666-72.

35. Zarafonetis CJ, Dabich L, Negri D, et al. Retrospective studies in scleroderma: effect of potassium paraaminobenzoate on survival. J Clinical Epidemiology. 1988;41:193-205.

36. Zarafonetis CJ, Dabich L, Devol EB, et al. Retrospective studies in scleroderma: pulmonary findings and effect of potassium p-aminobenzoate on vital capacity. Respiration; international review of thoracic diseases. 1989;56:22-33.

37. Clegg DO, Reading JC, Mayes MD, et al. Comparison of aminobenzoate potassium and placebo in the treatment of scleroderma. The Journal of rheumatology. 1994;21:105-10.

\section{*Correspondence to:}

Khalid Sawalha

Department of Neurology

Ohio State University Wexner Medical Center

395 W. 12th Avenue, 7th Floor

Columbus, $\mathrm{OH} 43210$

USA

E-mail: khalid.sawalha@osumc.edu 